\title{
A Case of Voice Therapy for Patient Who Voice Changed after Total Thyroidectomy Using Contactless Voice and Speech Therapy Service Platform
}

\author{
GilJoon Lee (iD) and Su Na Park (D)
}

Department of Otorhinolaryngology-Head and Neck Surgery, Chilgok Kyungpook National University Hospital, Kyungpook National University School of Medicine, Daegu, Korea

\author{
갑상선 수술 후 음성 변화에 대한 비대면 음성언어치료 증례 \\ 이길준, 박수나 \\ 경북대학교 의과대학 칠곡경북대학교병원 이비인후-두경부외과학교실
}

Voice therapy is effective in many voice and speech disorders. However, patients have low accessibility to therapeutic facilities due to disease-unrelated reasons such as lack of time and pandemic of COVID-19. Contactless voice therapy could be an alternative and may helpful to all patients with voice and speech problems. We developed contactless voice and speech therapy program on the necessity of improving accessibility. Herein, we report the first case of voice therapy to 30 year-old female patient who complained voice change after total thyroidectomy using contactless voice and speech therapy service platform in Korea.

Keywords Voice therapy; Contactless; Voice disorder.

\section{서 론}

음성언어질환은 후두, 구인두 등 발성기관, 호흡기계의 다양한 원인에 의해 발생하는 매우 흔한 질환이다[1,2]. 음성언어질환은 생명에 직접적인 영향을 주는 치명적인 질병인 경우는 많지 않지만, 특히 음성을 전문적으로 사용하는 직군에 종사하는 사람들에게는 생계와 관련하여 사회적인 문제와도 연관될 수가 있다. 하지만 많은 경우 적절한 시기에 치료를 받으면 회복되는 경우가 많다[2,3].

음성언어치료는 장기간의 시간과 반복적인 훈련을 요구하는 경우가 많다[4,5]. 하지만 개인 및 사회적 여건상 충분한 시공간적 환경이 제공되지 못하는 것이 현실이다. 예컨 대 언어발달 지연으로 언어치료가 필요한 소아 환자의 경우 환아 스스로 병원이나 언어 치료실에 방문하여 치료를 받을 수 없으므로 보호자가 반드시 필요한데 보호자는 환아 의 치료를 위해 별도의 시간을 할애하여야 한다. 소아 언어치료와 같은 경우 장기간 꾸준 한 훈련을 통한 치료가 필요하다. 만약 환아의 보호자가 모두 직장생활을 하는 직장인이
Received October 27, 2020

Revised November 30, 2020

Accepted January 6, 2021

Corresponding Author

GilJoon Lee, MD

Department of Otorhinolaryngology-

Head and Neck Surgery,

Chilgok Kyungpook National

University Hospital,

Kyungpook National University

School of Medicine,

807 Hoguk-ro, Buk-gu,

Daegu 41404, Korea

Tel +82-53-200-2166

$\mathrm{Fax}+82-53-200-2027$

E-mail giljoon.lee@gmail.com

ORCID iDs

GilJoon Lee (D)

https://orcid.org/0000-0002-3344-1879

Su Na Park (D)

https://orcid.org/0000-0002-1127-319X

This is an Open Access article distributed under the terms of the Creative Commons Attribution Non-Commercial License (https://creativecommons.org/ licenses/by-nc/4.0) which permits unrestricted non-commercial use, distribution, and reproduction in any medium, provided the original work is properly cited. 
라면 우리나라의 사회구조상 언어치료를 위해 규칙적으로 시 간을 할애하기가 어려운 경우가 많다. 시간을 할애한다 하더 라도 생활권 주변에 언어치료가 가능한 시설이 없다면 치료 를 받기 어렵다. 뇌병변으로 인해 거동이 불편한 노인 환자가 음성언어장애를 동반하고 있는 경우도 흔하게 경험한다. 치 료를 위해 병원이나 언어치료실을 방문하는 경우 소요되는 시간과 보조 인력 및 이동 시 필요한 장비 등에 대한 부담 등 을 고려한다면 음성언어치료를 적극적으로 시행하기가 부담 스러울 수 있다[6]. 일반 성인들의 경우 직장생활 문제로 병원 이나 음성언어치료실을 방문할 시간이 부족하거나 생활권 주 변에 치료 시설이 없는 경우 치료하기가 쉽지 않다. 또한, 최근 COVID-19의 전 세계적 유행으로 인하여 사회 전반적으로 비대면 활동이 요구되고 있다. 이미 여러 기관에서 비대면 음 성언어치료는 꾸준히 시도되어 왔고 스마트폰 등 온라인 미 디어 환경이 급속도로 발전한 2010년 이후에는 이러한 기술 적 발전과 더불어 비대면 음성언어치료의 치료 효과에 대한 긍 정적인 연구 결과들이 보고되었다[7-9].

본 저자들은 음성언어질환에 대한 비대면 음성언어치료의 시대 사회적인 요구와 필요, 그리고 대면 치료와 더불어 치료 효과를 상승시키기 위하여 비대면 치료를 계획하고 치료 프 로그램을 개발하여 실제 임상 치료에 적용하였다. 비대면 음 성언어치료 프로그램은 칠곡경북대학교병원 이비인후과 및 음성언어치료실(Daegu, Korea), 대구대학교 언어치료학과 (Daegu, Korea)와 (주)네오폰스(Daegu, Korea)가 공동 개발 한 토키토키(talkytalky) 프로그램을 이용하여 진행하였다.

토키토키는 비대면 음성언어치료를 위한 프로그램으로 컴 퓨터 웹사이트 및 스마트폰 애플리케이션에서 모두 접근이 가 능하며 환자가 등록된 언어재활사 중 1 명을 선택하여 환자와 언어재활사가 1 대 1 로 연결되어 치료가 진행되는 구조로 되어 있다.

프로그램 내 병원이나 언어치료실에서 시행하고 있는 음성 언어치료법이 탑재되어 있어, 언어재활사가 필요한 치료 도구 를 선택하여 사용할 수 있다. 치료는 Zoom 프로그램(https:// Www.zoom.us/)을 이용한 비대면 화상 치료로 진행되며 영 상 지원이 되지 않는 경우 음성 연결이나 대화창을 이용하여 환자와 언어재활사 간의 의사소통이 가능하다. 또한 언어재 활사가 과제를 제시할 수 있고 환자는 해당 과제를 문서, 동 영상, 음성 등 다양한 형태로 수행할 수 있으며 수행 과제에 대해 언어재활사와 상담하는 피드백(feedback) 과정을 거치 도록 구성되어 있다.

본 저자들은 음성언어질환을 않고 있는 환자들에 대해 토 키토키 프로그램을 이용하여 2020년 7월부터 비대면 음성언 어치료를 국내에서 처음으로 시행하고 있으며 이 중 갑상선
수술 후 음성 변화를 보이는 환자에서의 음성치료 증례를 보 고 하고자 한다.

\section{증 례}

30세 여자 환자가 수개월 이상 지속되는 목소리 변성 및 주 소로 내원하였다. 환자는 2020년 4월 갑상선 유두암으로 본 원 외과에서 갑상선 전절제술과 전경부 림프절 절제술을 시 행받았으며 당시 우측 되돌이 후두신경에의 종양 침범으로 우측 되돌이 후두신경을 절제한 상태였다. 후두 내시경 소견 상 우측 성대마비(vocal cord palsy, paramedian fixation)가 관찰되었으며 좌측 성대 움직임도 $30 \%$ 정도 감소되어 있었다. 흡기 시 천명음이 확인되었으나 주관적인 호흡곤란은 호소하 지 않았다. 환자가 목소리 변성에 대한 불편감과 발성 시 피로 감에 대한 개선을 원하여 음성치료를 시행하기로 결정하였다. 치료 전 음성 평가를 시행하였고 주관적 음성 평가로 음성장 애지수(voice handicap index)를 평가하였고 40점으로 전반 적인 음성 만족도는 낮았다. 공기역학적 평가에서 최대발성시 간(maximum phonatory time)은 $14.71 \mathrm{sec}$, 평균호기류율 (mean airflow ratio)은 $40 \mathrm{~mL} / \mathrm{sec}$ 로 감소되어 있었고 성문하 압(subglottal pressure) $8.49 \mathrm{~cm} / \mathrm{H} 2 \mathrm{O}$ 로 평균 이상 증가된 수 치로 측정되었다. 청지각적 평가(grade, roughness, breathiness, asthenia, strain scale; GRBAS)에서는 G1R0B1A0S0 로 비교적 양호하게 평가되었다. 음향학적 평가도 시행하였고 기본주파수(fundamental frequency) $204.890 \mathrm{~Hz}$, 주파수변 동률(jitter) $1.694 \%$, 진폭변동률(shimmer) 4.312\%, 배음 대 잡음비(noise to harmonic ratio)는 0.111로 측정되었다.

음성치료는 본원 이비인후과 음성언어치료실 소속 언어재 활사 1 인에 의해 2020년 7월 9월까지 9주에 걸쳐 시행되었 다. 언어재활사와의 상담 후 후두마사지를 통한 근육 이완, 복식호흡을 통한 발성 연습과 성대기능 훈련을 실시하여 후 두근 강화를 유도하는 치료를 위주로 진행하였다. 치료는 병원에서 시행하는 대면 치료를 주 1 회 시행하고 가정에서 토 키토키 애플리케이션을 이용한 비대면 치료를 주 1 회 시행하 였다. 비대면 치료는 Zoom을 이용한 화상 대면 치료(Fig. 1)로 진행하였고 환자와 언어재활사 간 원활한 의사소통이 가능하 도록 소음이 없는 실내 공간에서 이루어지도록 지도하였다. 또한 온라인상의 과제 등록과 이에 대한 언어재활사의 피드 백을 통한 학습과 훈련을 하는 방식으로 진행되었다(Fig. 2).

치료 9주 후 평가에서 환자는 목 불편감이 호전되었고 음성 도 호전되었다고 표현하였으며 VHI는 치료 전 40점에서 치료 후 8점으로 음성 만족도가 상승한 것으로 평가되었다. 후두 내시경 소견상 좌측 성대움직임이 $70 \%$ 정도로 호전되었고 
음성 검사상 최대발성시간은 $21.93 \mathrm{sec}$ 로 증가하였고 평균호 기류율은 $30 \mathrm{~mL} / \mathrm{sec}$, 성문하압 $9.10 \mathrm{~cm} / \mathrm{H} 2 \mathrm{O}$ 로 큰 변화는 없 었다. GRBAS는 GOROBOAOSO으로 호전되었고 음향학적 평 가에서 발성 가능한 음역 범위가 확장되었으며(Fig. 3) 기본주 파수 $234.951 \mathrm{~Hz}$, 주파수변동률 $0.855 \%$, 진폭변동률 4.614\%,

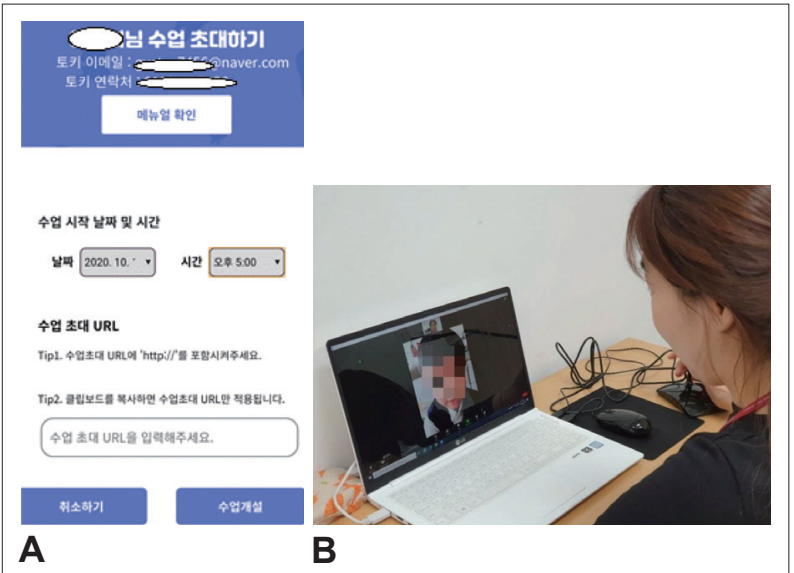

Fig. 1. Contactless voice therapy using telecommunication system. A: First step to pratice. B: Telepractice between patient and speechlanguage pathologist.

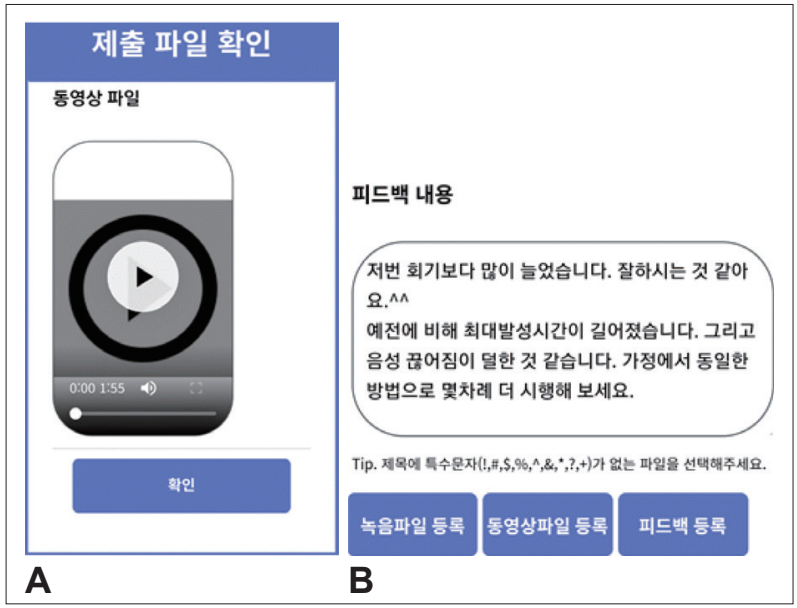

Fig. 2. Feedback process with task between SLP and patient. A: Uploaded task of self-training by patient. B: Feedback for the task of patient by SLP. SLP: speech-language pathologist.
배음 대 잡음비는 0.134로(Fig. 4) 치료 후 음성 평가에서 전반 적인 호전 소견을 확인하였다. 현재 비대면 음성언어치료 시 작 후 3개월이 경과한 상태로 주관적으로 만족할 만한 음성 개 선을 보여 음성치료를 종료하고 외래에서 경과 관찰 중이다.

\section{고 찰}

음성언어질환에 대한 치료 성과는 질환의 종류와 적절한 치료 방법 여부도 중요하지만 장기간에 걸쳐 많은 시간과 비용 이 요구되는 특성상 환자의 순응도도 중요한 요인 중 하나이 다. 그리고 환자 순응도를 결정하는 가장 중요한 요인은 인터 넷 환경에 대한 접근성이다. 비대면 음성언어치료는 컴퓨터와 스마트폰 등의 기기가 필요하며 화상 애플리케이션을 활용하 고 환자 스스로 부여받은 과제를 문서나 동영상, 음성 파일 의 형태로 등록할 수 있는 능력이 요구된다. 청소년이나 청장 년층 환자들은 이러한 환경에 익숙하여 접근하기 용이하지만 노인이나 소아 환자들에게는 거부감을 줄 수 있다. 본 증례 환 자는 젊은 여성으로 최신 기기나 비대면 환경에 대한 이해도 가 높았고 따라서 비대면 치료를 진행하는 데 어려움은 없었 지만 고령 혹은 소아 환자의 경우를 가정하였을 때 치료 과정 에 대한 전반적인 교육이 필수적이고 방법에 대해 명확히 주 지시켜야 한다는 것을 예상할 수 있다.

또한 대면 치료에서는 치료사와 환자가 한 공간에서 소통 하며 정서상의 유대감을 형성할 수 있는 장점이 있는 반면 비 대면 치료는 이러한 점에서는 일부 불리할 수 있다. 특히, 소 아 음성언어치료에서는 환아와 언어재활사 간의 공감대를 형 성하며 정서를 교류하는 것이 중요한데 화상 대면을 한다고 하더라도 같은 공간에서 마주보고 치료를 진행하는 것이 아 니므로, 이러한 점이 치료의 효율성을 감소시킬 가능성을 염 두해야 하고 극복 방안을 모색해야 한다.

음성언어치료에 대한 비대면 치료는 이제 시작 단계이다. 현 시점에서 대면 치료만큼의 효과를 기대하기는 어려우며 시행 을 하더라도 대면 치료와 병행해야만 한다. 비대면 치료 도구

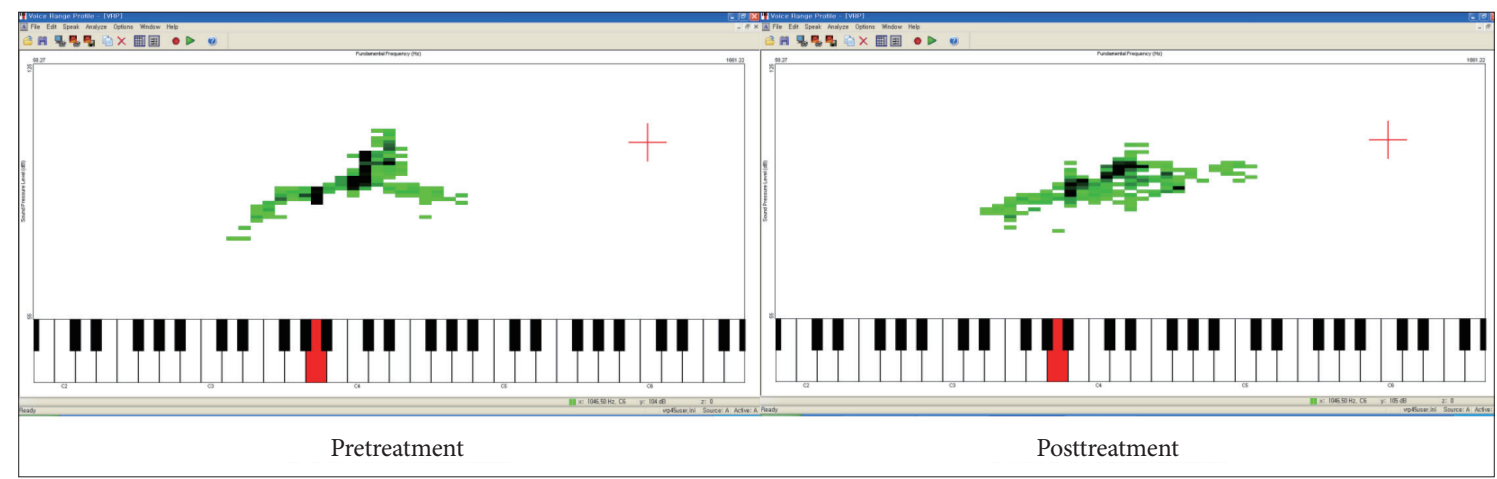

Fig. 3. Voice range profile. Range is improved at high and low pitch area after contactless voice therapy. 


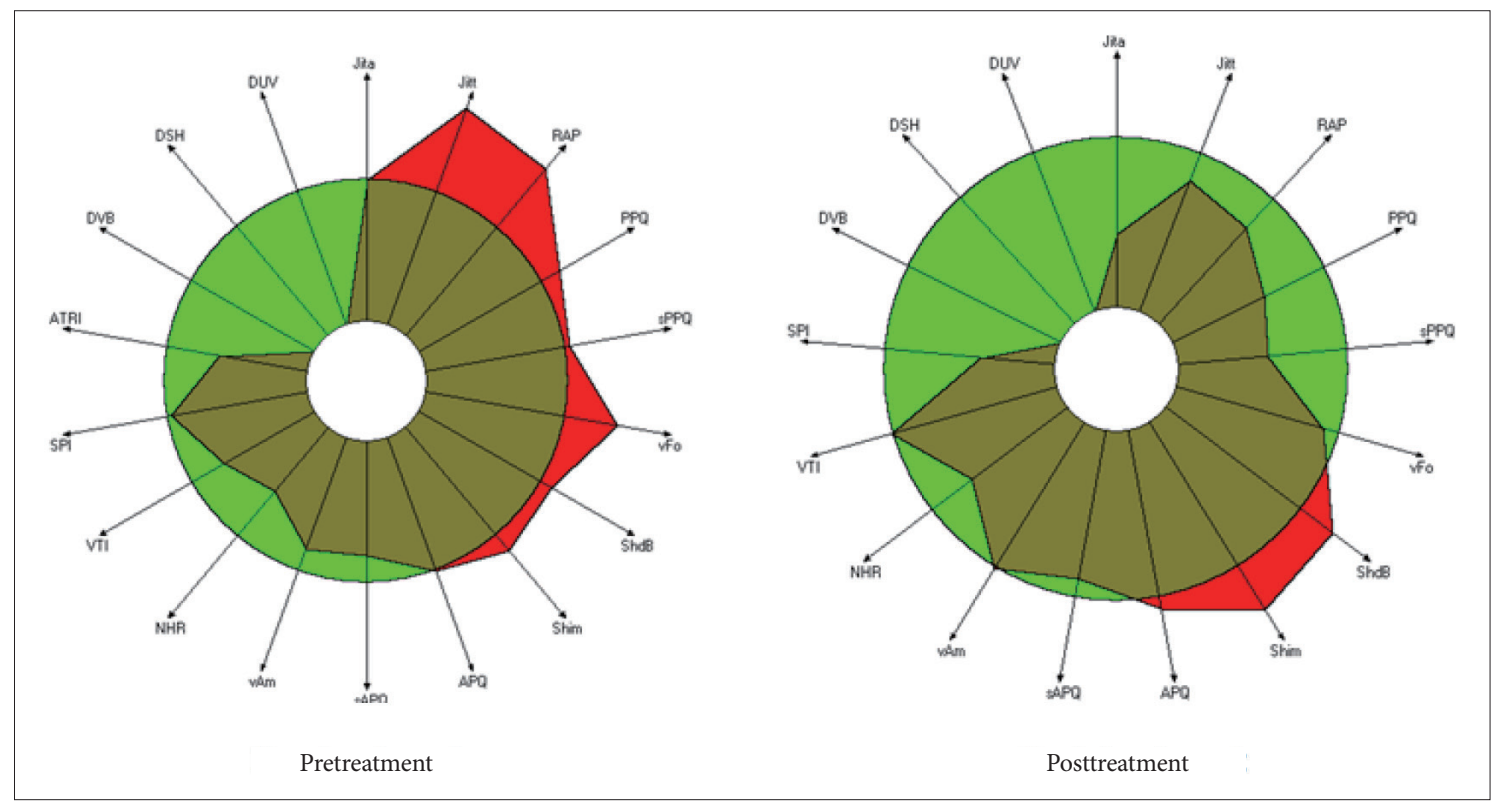

Fig. 4. Multi dimensional voice program. Graphs shows voice quality is improved after contactless voice therapy.

의 기술적 한계로 인해 자가 훈련 정도의 수준인 것이 현실이 다. 또한, 앞서 언급한 대로 비대면 치료 환경에 대한 이해도 부 족이나 대면 치료만큼 공감대를 형성하기 어려운 단점도 있지 만, 치료가 가능함에도 불구하고 바쁘고 복잡한 일상 때문에 장기간에 걸쳐 수 차례 시간을 할애할 수 없어 치료를 포기하 는 환자들에게 비대면 치료는 좋은 대안이 될 수 있다[10-12]. 비대면 치료는 시공간적 한계를 극복하는 장점이 있다. 바쁜 일상으로 병원이나 언어치료실을 방문할 시간이 부족한 환자 나 거동이 불편하거나 보호자가 없으면 이동하기 힘든 소아 환자, 현재와 같은 COVID-19의 유행 등 특수한 상황에서 발 생할 수 있는 공간적 제약을 극복 가능하게 한다. 국내외 연구 들에서 시공간적 제약을 극복 가능하게 하는 비대면 치료의 효과를 보고하고 있고[8] 의사소통이 원활하지 않아 비대면 환경에서 치료하기 어려울 것이라고 예상하는 신경계 장애 환 자 및 자폐 환아나 언어발달장애 환아 등에서 비대면 음성언 어치료의 긍정적 효과를 보고하였다[13-15]. 또한 최근 인공 지능 기술의 발전으로 시공간적 제약에 대한 초월을 더욱 가 속화하게 될 것이고 비대면 치료의 영역도 현재보다 발전된 형 태로 보완될 것이다. 따라서 가까운 미래에 비대면 환경에서 마치 대면하고 있는 것과 같은 상황을 구현해낼 수 있을 것으 로 기대한다.

본 증례가 단일 증례이고 비대면 음성언어치료의 효과를 평 가하기에 한계가 있으나 성대결절이나 용종 등 장기적, 반복 적 음성치료가 효과적인 질환에 비대면 치료를 적용하는 것 이 도움이 될 것이라 사료된다. 이번 증례보고를 기점으로 장 기적으로 다양한 음성질환의 비대면 음성언어치료에 대한 데
이터를 수집, 분석하여 비대면 치료로 인해 발생하는 단점을 최소화하고 대면 치료의 장점은 최대한 수용하여 보완하는 과정이 필수적이며 이를 위해 후속 연구를 지속적으로 진행 할 계획이다.

중심 단어: 음성치료, 비대면, 음성질환.

Acknowledgments

None.

Conflicts of Interest

The authors have no financial conflicts of interest.

Authors' Contribution

Conceptualization: all authors. Writing-original draft: GilJoon Lee. Writing - review \& editing: GilJoon Lee. Approval of final manuscript: all authors.

\section{REFERENCES}

1. Zraick RI, Risner BY. Assessment of quality of life in persons with voice disorders. Curr Opin Otolaryngol Head Neck Surg 2008;16(3):188-93.

2. Ahn CM, Shin IS, Shin JE. The study of satisfaction of voice therapy in patients with voice disorders. J Korean Soc Laryngol Phoniatr Logop 2016;27(1):35-39.

3. Roy N, Merrill RM, Gray SD, Smith EM. Voice disorders in the general population: prevalence, risk factors, and occupational impact. Laryngoscope 2005;115(11):1988-95.

4. Ahn CM, Park JW, Lee JH, Lee YB, Park HJ. Therapeutic effects of voice therapy on functional voice disorders. Korean J Otorhinolaryngol-Head Neck Surg 1996;39(2):288-94.

5. Yoon JH, Kim SW. A survey on participants' satisfaction of vocal hygiene education: a preliminary study. Phonetics Speech Sci 2013;5(3): 83-93.

6. Morrell K, Hyers M, Stuchiner T, Lucas L, Schwartz K, Mako J, et al. Telehealth stroke dysphagia evaluation is safe and effective. Cerebrovasc Dis 2017;44(3-4):225-31. 
7. Choi YH, Park HK, Paik NJ. A telerehabilitation approach for chronic aphasia following stroke. Telemed J E Health 2016;22(5):434-40.

8. Lee HN, Yoo JY, Park JH. Effect of online and offline voice therapy programs in patients with hyperfunctional voice disorder: a case study. Commun Sci Disord 2019;24(3):814-26.

9. Bae IH, Lee JA, Park HJ, Kwon SB. Development of a platform for augmented reality-based speech language therapy. Commun Sci Disord 2018;23(2):462-76.

10. Grogan-Johnson S, Alvares R, Rowan L, Creaghead N. A pilot study comparing the effectiveness of speech language therapy provided by telemedicine with conventional on-site therapy. J Telemed Telecare 2010;16(3):134-9.

11. Kim SJ, Kim MJ, Ha S, Ha JW. A survey of speech sound disorders in clinical settings. Commun Sci Disord 2015;20(2):133-44.
12. Mashima PA, Birkmire-Peters DP, Syms MJ, Holtel MR, Burgess LP Peters LJ. Telehealth: voice therapy using telecommunications technology. Am J Speech Lang Pathol 2003;12(4):432-9.

13. Grogan-Johnson S, Meehan R, McCormick K, Miller N. Results of a national survey of preservice telepractice training in graduate speechlanguage pathology and audiology programs. Contemp Issues Commun Sci Disord 2015;42:122-37.

14. Tohidast SA, Mansuri B, Bagheri R, Azimi H. Provision of speech-language pathology services for the treatment of speech and language disorders in children during the COVID-19 pandemic: problems, concerns, and solutions. Int J Pediatr Otorhinolaryngol 2020;138:110262.

15. Tucker JK. Perspectives of speech-language pathologists on the use of telepractice in schools: the qualitative view. Int J Telerehabil 2012;4(2): 47-60. 